ORIGINAL ARTICLE

\title{
TLR4 and TNF- $\alpha$ polymorphisms are associated with an increased risk for severe sepsis following burn injury
}

\author{
R C Barber, C C Aragaki, F A Rivera-Chavez, G F Purdue, J L Hunt, J W Horton
}

J Med Genet 2004;41:808-813. doi: 10.1136/jmg.2004.021600

See end of article for authors' affiliations

....................

Correspondence to: Dr Robert C Barber, UT Southwestern Medical Center, Department of Surgery, 5323 Harry Hines Blvd, Dallas, TX 75390-9160, USA: robert.barber@ utsouthwestern.edu

Revised version received 2 June 2004

Accepted for publication 18 June 2004

\begin{abstract}
Context: Sepsis, organ failure, and shock remain common among patients with moderate to severe burn injuries. The inability of clinical factors to identify at-risk patients suggests that genetic variation may influence the risk for serious infection and the outcome from severe injury.

Objective: Resolution of genetic variants associated with severe sepsis following burn injury.

Patients: A total of 159 patients with burns $\geqslant 20 \%$ of their total body surface area or any smoke inhalation injury without significant non-burn related trauma (injury severity score (ISS) $\geqslant 16$ ), traumatic or anoxic brain injury, or spinal cord injury and who survived more than $48 \mathrm{~h}$ post-admission.

Methods: Candidate single nucleotide polymorphisms (SNPs) within bacterial recognition (TLR4 +896, CD14 - 159) and inflammatory response (TNF- $\alpha-308$, IL-1 $\beta-31$, IL-6 - 174) loci were evaluated for association with increased risk for severe sepsis (sepsis plus organ dysfunction or septic shock) and mortality.

Results: After adjustment for age, full-thickness burn size, ethnicity, and gender, carriage of the TLR4 +896 G-allele imparted at least a 1.8-fold increased risk of developing severe sepsis following a burn injury, relative to $\mathrm{AA}$ homozygotes (adjusted odds ratio (aOR) 6.4; 95\% confidence interval (CI) 1.8 to 23.2). Carriage of the TNF- $\alpha-308$ A-allele imparted a similarly increased risk, relative to GG homozygotes ( $\mathrm{aOR}=4.5 ; 95 \% \mathrm{Cl} 1.7$ to 12.0 ). None of the SNPs examined were significantly associated with mortality. Conclusions: The TLR4 +896 and TNF- $\alpha-308$ polymorphisms were significantly associated with an increased risk for severe sepsis following burn trauma.
\end{abstract}

B urn trauma is an important cause of morbidity and mortality worldwide. Sepsis, organ failure, and shock remain common among patients with moderate to severe burn injuries, despite a greater understanding of post-burn resuscitation, organ system support, and burn wound treatment. Sepsis accompanied by organ failure carries a $30-50 \%$ case-fatality rate and those patients who do survive often require prolonged and costly medical care. ${ }^{1-5}$ Although we have gained an increased understanding of the pathophysiological processes that follow burn injury and a wealth of information concerning the clinical factors that predispose burn victims to severe sepsis and septic shock, we are still unable to predict accurately which patients will follow a complicated clinical course.

The inability of clinical factors to identify at-risk patients suggests that genetic variation may influence the risk for serious infection and the outcome from severe injury. ${ }^{6}$ Indeed, associations between specific genetic variants and outcome following serious injury and infection have been reported. $^{7-9}$

Burn trauma offers certain advantages for the study of such associations. Notable among these is the highly quantifiable nature of the injury, in terms of burn depth and extent (burn size). The simple expression of burn size as a percentage of total body surface area (TBSA) adjusts for individual variation in body mass, enabling the direct comparison of patients. In addition, associated smoke inhalation can be diagnosed accurately. Finally, the typical burn patient is relatively young and free from comorbidity prior to the burn injury.

Identification of genetic polymorphisms that predispose burn patients to the most severe manifestations of infection would allow early targeting of high risk individuals for aggressive or novel treatment, potentially improving their clinical outcome. Eventually, rapid genetic screening of patients may enable physicians to tailor treatment to the individual, rather than the injury.

Selection of candidate single nucleotide polymorphisms (SNPs) was based upon location within a biologically relevant locus and evidence of a functional effect. Candidate SNPs were located within genes responsible for microbial recognition (TLR4 and CDI4), as well as cytokine loci that are known to mediate the inflammatory response (TNF- $\alpha$, IL-1 $\beta$, and IL-6). In addition, candidate SNPs had at least one report of an effect upon protein function or abundance or a previous report of an association with an inflammation or immune response related phenotype. ${ }^{10-19}$

\section{METHODS}

Study design and data collection

Patients admitted to the burn intensive care unit (BICU) unit at Parkland Memorial Hospital (Dallas, TX) with any smoke inhalation injury or with $\geqslant 20 \%$ TBSA burns were prospectively enrolled between April 1999 and December 2003, under a protocol approved by the Institutional Review Boards of the University of Texas Southwestern Medical Center and Parkland Memorial Hospital that waived the requirement for informed consent. In order to remove confounding variables that were unrelated to burn injury, individuals were excluded if they presented with significant non-burn related trauma (injury severity score (ISS) $\geqslant 16$ ), traumatic or anoxic brain injury, spinal cord injury, or if they failed to survive more than $48 \mathrm{~h}$ post-admission.

Clinical data were recorded daily and stored in a computerised database, concurrent with admission to the

Abbreviations: aOR, adjusted odds ratio; $\mathrm{BICU}$, burn intensive care unit; ISS, injury severity score; LPS, lipopolysaccharide; PCR, polymerase chain reaction; SNPs, single nucleotide polymorphisms; TBSA, total body surface area 
BICU. These data were supplemented with information from the prospectively maintained burn registry and the BICU database. The ISS is an index of injury severity that ranges from 0 to 75 , with a value equal to or greater than 16 indicating severe injury. ${ }^{20}$

\section{DNA isolation and genotyping}

Venous blood samples were collected into EDTA and genomic DNA was isolated by standard protocols. ${ }^{21}$ Fragments containing each of the SNPs were amplified from genomic DNA by polymerase chain reaction (PCR) using Taq DNA polymerase (Roche Diagnostics, Indianapolis, IN). All amplifications were carried out in a PTC 200 thermal cycler (MJResearch, Watertown, MA) using a thermal profile, reaction conditions, and primer sequences that were optimised for each SNP (table 1). All the genotypes examined in this study were determined by Pyrosequencing (Pyrosequencing AB, Westborough, MA). Pyrosequencing is a DNA sequencing technique that is based upon the detection of pyrophosphate, which is released in direct proportion to the number of incorporated nucleotides during DNA synthesis. The energy retained by pyrophosphate was utilised in an enzymatic cascade to cleave a targeted substrate and produce visible light. The quantity of light produced was measured and genotypes were resolved using PSQ 96 SNP Software, v 1.2 AQ. Each SNP was assayed with a specific primer sequence (table 1 ), which enabled the scoring of heterozygotes and alternate homozygotes with equal reliability. ${ }^{22}$ In addition, a representative sample of genotypes at each SNP was confirmed by restriction fragment length polymorphism and/or sequence analysis (data not presented).

\section{Quantification of sepsis severity}

Sepsis was defined according to the American College of Chest Physicians/Society of Critical Care Medicine consensus definitions. Severe sepsis was defined as sepsis that was temporally accompanied by the need for intravenous vasopressor drug support (excluding dopamine at $\leqslant 5 \mu \mathrm{g} / \mathrm{kg} / \mathrm{min}$ ) to maintain blood pressure (despite adequate fluid resuscitation) along with the presence of perfusion abnormalities, or metabolic acidosis $(\mathrm{pH} \leqslant 7.30)$ or the development of respiratory, renal, hepatic, or haematological failure. Specifically, a patient was considered to have sepsis related organ failure if a Marshall organ dysfunction score of $\geqslant 3$ (failure) was assigned in one or more organs concurrent with, or within $48 \mathrm{~h}$ of, the diagnosis of sepsis. ${ }^{23}$ Mild sepsis was defined as sepsis without any evidence of organ dysfunction or the need for intravenous vasopressor drug support to maintain blood pressure. Inhalation injury was defined as a history of being burned in a closed, smoke filled space, with or without positive bronchoscopy and acute respiratory distress syndrome (bilateral fluffy infiltrates in the absence of congestive heart failure, $\mathrm{P}: \mathrm{F}<200$, and the need for more than $96 \mathrm{~h}$ of mechanical ventilation, independent of airway protection).

\section{Data analysis}

Data analysis was performed using SPSS 10.1 (SPSS, Chicago, IL) and SAS 8.02 (SAS Institute, Cary, NC) statistical software. Descriptive statistics included counts and percentages for categorical variables and medians with associated 25th and 75th quartiles for continuous data. Categorical data were compared using the $\chi^{2}$ test, while continuous data were compared by Mann-Whitney U. Best sets multiple logistic regression was used to simultaneously evaluate the effects of multiple variables as risk factors for severe sepsis. Actual p values are reported for all analyses. The adjusted odds ratios (aORs) obtained from the regression analysis are presented with their associated 95\% confidence intervals. Due to the low allele frequencies, homozygous carriers of the TNF- $\alpha-308 \mathrm{~A}-$, TLR $4+896 \mathrm{G}-$, and IL- 6 - 174Calleles were grouped with heterozygotes for analysis. Alternate homozygotes at the more common IL-1 $\beta-31$ and CD14 - 159 SNPs were analysed separately from heterozygotes. The IL-1 $\beta$ and CDI4 SNPs were analysed both ways and the results did not differ (data not presented).

\section{RESULTS}

Demographics and clinical outcomes

Between April 1, 1999 and December 31, 2003, 159 patients admitted to the BICU at Parkland Memorial Hospital, Dallas, TX with $\geqslant 20 \%$ TBSA burns or any inhalation injury were enrolled. A subgroup of these patients was included in a previous report concerning the clinical features of sepsis and organ failure after burn trauma. ${ }^{24}$ Demographic and clinical outcome data are summarised in table 2 and described briefly below. Of the 159 patients, 25 (16\%) died. The major causes of injury were flame $(63 \%)$ or scalding $(21 \%)$.

Table 1 Polymerase chain reaction (PCR) primer sequences, PCR amplification conditions, and lengths for each of the candidate SNP amplimers

\begin{tabular}{|c|c|c|c|}
\hline Locus & Amplimer length & Primer sequences & Cycling conditions \\
\hline TNF- $\alpha-308$ & $107 \mathrm{bp}$ & $\begin{array}{l}\text { PCR (For): AGGCAATAGGTाTGGAGGGCCAT } \\
\text { PCR (Rev): TCCTCCCTGCTCCGATTCCG } \\
\text { Pyrosequencing (Rev): GGCTGAACCCCGTCC }\end{array}$ & $\begin{array}{l}\text { One cycle: } 95^{\circ} \mathrm{C}-4 \mathrm{~min} ; 35 \text { cycles: } 95^{\circ} \mathrm{C}-3 \mathrm{~s}, \\
60^{\circ} \mathrm{C}-30 \mathrm{~s}, 74^{\circ} \mathrm{C}-30 \mathrm{~s} ; \text { one cycle: } 74^{\circ} \mathrm{C}-6 \mathrm{~min}\end{array}$ \\
\hline IL-6 - 174 & $111 \mathrm{bp}$ & $\begin{array}{l}\text { PCR (For): CGCTAGCCTCAATGAC } \\
\text { PCR (Rev): CGGGTGGGGCTGATTGGAA } \\
\text { Pyrosequencing (For): CCCTAGTTGTGTCTTGC }\end{array}$ & $\begin{array}{l}\text { One cycle: } 95^{\circ} \mathrm{C}-4 \mathrm{~min} ; 35 \text { cycles: } 95^{\circ} \mathrm{C}-45 \mathrm{~s}, \\
63^{\circ} \mathrm{C}-30 \mathrm{~s}, 74^{\circ} \mathrm{C}-45 \mathrm{~s} ; \text { one cycle: } 74^{\circ} \mathrm{C}-6 \mathrm{~min}\end{array}$ \\
\hline IL-1 $\beta-31$ & $222 \mathrm{bp}$ & $\begin{array}{l}\text { PCR (For): CCTCCTACTCTGCTTTGAAGGC } \\
\text { PCR (Rev): AAGAGAGAGAGAGAGAGAATATGC } \\
\text { Pyrosequencing (Rev): TCCCTCGCTGTITITA }\end{array}$ & $\begin{array}{l}\text { One cycle: } 95^{\circ} \mathrm{C}-4 \mathrm{~min} ; 35 \text { cycles: } 95^{\circ} \mathrm{C}-30 \mathrm{~s}, \\
55^{\circ} \mathrm{C}-30 \mathrm{~s}, 74^{\circ} \mathrm{C}-30 \mathrm{~s} ; \text { one cycle: } 74^{\circ} \mathrm{C}-6 \mathrm{~min}\end{array}$ \\
\hline CD14-159 & $193 \mathrm{bp}$ & $\begin{array}{l}\text { PCR (For): ATCATCCTTTCCCCACACC } \\
\text { PCR (Rev): GCCCCCTTCCTTCCTGGA } \\
\text { Pyrosequencing (Rev): TTCAGGGAGGGGG }\end{array}$ & $\begin{array}{l}\text { One cycle: } 95^{\circ} \mathrm{C}-4 \mathrm{~min} ; 35 \text { cycles: } 95^{\circ} \mathrm{C}, 30 \mathrm{~s}, \\
64^{\circ} \mathrm{C}-30 \mathrm{~s}, 74^{\circ} \mathrm{C}-30 \mathrm{~s} ; \text { one cycle: } 74^{\circ} \mathrm{C}-6 \mathrm{~min}\end{array}$ \\
\hline TLR4 +896 & $193 \mathrm{bp}$ & $\begin{array}{l}\text { PCR (For): AGTCCATCGITGGTTCTGG } \\
\text { PCR (Rev): CACACTCACCAGGGAAAATG } \\
\text { Pyrosequencing (Rev): ACAATTAAATAAGTCAATAA }\end{array}$ & $\begin{array}{l}\text { One cycle: } 95^{\circ} \mathrm{C}-4 \mathrm{~min} ; 35 \text { cycles: } 95^{\circ} \mathrm{C}-60 \mathrm{~s}, \\
55^{\circ} \mathrm{C}-60 \mathrm{~s}, 74^{\circ} \mathrm{C}-60 \mathrm{~s} ; \text { one cycle: } 74^{\circ} \mathrm{C}-6 \mathrm{~min}\end{array}$ \\
\hline
\end{tabular}


Table 2 Summary statistics for demographic variables and clinical outcomes following burn injury for the entire sample of burn patients $(n=159)$

\begin{tabular}{lc}
\hline Demographic variable & Median/number \\
\hline Age & $35(21-47)$ \\
Male gender & $118(74 \%)$ \\
Ethnicity & \\
$\quad$ Caucasian & $90(57 \%)$ \\
Hispanic & $35(22 \%)$ \\
African American & $27(17 \%)$ \\
Other & $6(4 \%)$ \\
Percent of TBSA burned & $35(27-50)$ \\
Percent of TBSA full thickness burn & $20(9-45)$ \\
Inhalation injury & $52(33 \%)$ \\
Died & $25(16 \%)$ \\
ICU length of stay (days) & $19(6-33)$ \\
Length of stay total (days) & $31(16-50)$ \\
Duration of mechanical ventilation (days) & $12(3-24)$ \\
Severity of sepsis & \\
$\quad$ No sepsis & $54(34 \%)$ \\
Mild sepsis & $69(43 \%)$ \\
Severe sepsis & $36(23 \%)$ \\
\hline
\end{tabular}

Continuous data are presented as medians (25th-75th percentiles). Categorical data are presented as number of patients (percentage).

\section{Clinical risk factors for and outcome from severe sepsis}

Of the 159 patients, 36 (23\%) developed severe sepsis, defined as sepsis complicated by organ dysfunction or septic shock. Of these 36 patients with severe sepsis, 79\% had evidence of a clinically relevant Gram-negative, or a mixed Gram-negative/Gram-positive infection (table 3). One patient with severe sepsis had candidiasis and two patients had infections of unknown characteristics. In the majority (63\%) of patients, pneumonia was the cause of severe sepsis. Patients had relatively few comorbid medical conditions, with alcohol abuse $(n=28,18 \%)$ and hypertension $(n=23$, $14 \%$ ) being reported most commonly. Pre-existing liver, lung, and renal disease was uncommon $(<1 \%)$. Age, burn size, and gender were associated with severe sepsis.

\section{Association between SNPs and outcome of burn injury Unadjusted analysis}

Genotype frequencies for the candidate SNPs among patients with and without severe sepsis are shown in table 3 . The TNF- $\alpha-308$ A allele was associated with an increased risk for severe sepsis by unadjusted analysis. Patients who were carriers of the A-allele at TNF- $\alpha-308$ had a $41 \%$ risk (16/39) for severe sepsis versus a $17 \%$ risk $(20 / 120)$ for patients homozygous for the wildtype G-allele $(p=0.002)$. The unadjusted relative risk for severe sepsis associated with carriage of the TNF- $\alpha-308$ A-allele was 3.47 (95\% CI 1.56 to 7.73). Similarly, carriers of the TLR $4+896 \mathrm{G}$ had a slight, but non-significant increased risk (unadjusted relative risk $=2.46$, $95 \%$ CI 0.88 to 6.90$)$ for severe sepsis by unadjusted analysis $(p=0.08)$. Seven $(39 \%)$ of the $18 \mathrm{G}$ allele carriers developed severe sepsis, versus 29 (21\%) of the 141 AA homozygotes. Data for the remaining SNPs (CD14, IL- $1 \beta$, and IL-6), which were not significantly associated with outcome, are included in table 4.

\section{Logistic regression}

In order to evaluate the candidate SNPs in the context of other potential risk factors, we performed a best sets multivariate logistic regression. Adjusting for age, burn size, ethnicity, and gender, carriage of the TNF- $\alpha-308$ A-allele and the TLR4 +896 G-allele was significantly associated with an increased risk for severe sepsis. The aORs were 4.47 (95\% CI 1.67 to 11.96 ) and 6.41 (95\% CI 1.77 to 23.17) for the
Table 3 Summary statistics for demographic variables and clinical outcomes following burn injury for patients stratified into groups with no or mild sepsis versus severe sepsis $(n=159)$

\begin{tabular}{lllr}
\hline $\begin{array}{l}\text { Demographic } \\
\text { variable }\end{array}$ & $\begin{array}{l}\text { No or mild } \\
\text { sepsis }(\mathbf{n}=123)\end{array}$ & $\begin{array}{l}\text { Severe sepsis } \\
(\mathbf{n}=36)\end{array}$ & p Value \\
\hline $\begin{array}{l}\text { Age } \\
\text { Male gender }\end{array}$ & $33(20-45)$ & $41(32-56)$ & 0.013 \\
$\begin{array}{l}\text { Ethnicity } \\
\quad \text { Caucasian }\end{array}$ & $68(80 \%)$ & $20(56 \%)$ & 0.008 \\
$\quad$ Hispanic & $31(25 \%)$ & $25(69 \%)$ & 0.193 \\
$\quad \begin{array}{l}\text { African American } \\
\quad \text { Other }\end{array}$ & $20(16 \%)$ & $7(11 \%)$ & \\
$\begin{array}{l}\text { Percent of TBSA } \\
\text { burned }\end{array}$ & $6(5 \%)$ & $0(0 \%)$ & \\
$\begin{array}{l}\text { Percent of TBSA full } \\
\text { thickness burn }\end{array}$ & $14(6-34)$ & $34(12-54)$ & 0.006 \\
$\begin{array}{l}\text { Inhalation injury } \\
\text { Gram-negative/mixed } \\
\text { culture infection }\end{array}$ & $32(26 \%)$ & $14(39 \%)$ & 0.134 \\
$\begin{array}{l}\text { Died } \\
\text { ICU length of stay }\end{array}$ & $10(8 \%)$ & $27(75 \%)$ & 0.086 \\
(days) & $14(4-29)$ & $30(16-66)$ & $<0.001$ \\
$\begin{array}{l}\text { Length of stay total } \\
\text { (days) }\end{array}$ & $29(16-46)$ & $35(16-83)$ & 0.089 \\
$\begin{array}{l}\text { Days of mechanical } \\
\text { ventilation }\end{array}$ & $7(1-21)$ & $18(12-49)$ & $<0.001$ \\
\hline
\end{tabular}

Continuous data are presented as median (25th-75th percentiles). Categorical data are presented as number of patients (percentage). Exact $p$ values are presented for unadjusted comparisons of demographic and clinical outcome variables by $\chi^{2}$ or Mann-Whitney $U$.

Table 4 Comparison of genotype frequencies at candidate SNPs among patients with no or mild versus severe sepsis

\begin{tabular}{|c|c|c|c|}
\hline Polymorphism & $\begin{array}{l}\text { No or } \\
\text { mild } \\
\text { sepsis } \\
(n=123)\end{array}$ & $\begin{array}{l}\text { Severe } \\
\text { sepsis } \\
(n=36)\end{array}$ & $\begin{array}{l}\text { Unadjusted } \\
\text { value }\end{array}$ \\
\hline \multicolumn{4}{|c|}{ TNF- $\alpha-308 \mathrm{G} \rightarrow \mathrm{A}$ transition } \\
\hline Homozygous G $(n=120)$ & $100(83 \%)$ & $20(17 \%)$ & 0.002 \\
\hline A-allele carriers $(n=39)$ & $23(59 \%)$ & $16(41 \%)$ & \\
\hline \multicolumn{4}{|l|}{ TLR4 +896 A $\rightarrow G$ transition } \\
\hline Homozygous A $(n=141)$ & $112(79 \%)$ & $29(21 \%)$ & 0.080 \\
\hline G-allele carriers $(n=18)$ & $11(61 \%)$ & 7 (39\%) & \\
\hline \multicolumn{4}{|c|}{ IL-6 $-174 \mathrm{G} \rightarrow \mathrm{C}$ transversion } \\
\hline Homozygous $G(n=86)$ & $69(80 \%)$ & $17(20 \%)$ & 0.347 \\
\hline C-allele carriers $(n=73)$ & $54(74 \%)$ & $19(26 \%)$ & \\
\hline \multicolumn{4}{|l|}{$\mathrm{CD} 14-159 \mathrm{C} \rightarrow \mathrm{T}$ transition } \\
\hline Homozygous $C(n=52)$ & $36(69 \%)$ & $16(31 \%)$ & 0.095 \\
\hline Heterozygotes $(n=77)$ & $60(78 \%)$ & $17(22 \%)$ & \\
\hline Homozygous T $(n=30)$ & $27(90 \%)$ & $3(10 \%)$ & \\
\hline \multicolumn{4}{|l|}{ IL-1 $\beta-31 \mathrm{~T} \rightarrow \mathrm{C}$ transition } \\
\hline Homozygous $T(n=60)$ & $48(80 \%)$ & $12(20 \%)$ & 0.206 \\
\hline Heterozygotes $(n=67)$ & $54(81 \%)$ & $13(19 \%)$ & \\
\hline Homozygous $C(n=32)$ & $21(66 \%)$ & $11(34 \%)$ & \\
\hline
\end{tabular}

TNF- $\alpha-308$ A- and TLR4 +896 G-alleles, respectively (table 5). The SNPs within the CD14, IL-1 $\beta$, and IL-6 loci were not associated with increased risk for severe sepsis. Ethnicity, pre-existing medical conditions, and the presence of an inhalation injury did not affect risk. Clinical risk factors for severe sepsis did not differ significantly between alternate genotypes at the candidate SNPs. 
Table 5 Risk factors for the development of severe sepsis after burn injury following adjustment for multiple factors

\begin{tabular}{llll}
\hline Risk factor & OR & $\mathbf{9 5 \%} \mathbf{C l}$ & p Value \\
\hline TNF- $\alpha-308$ A-allele carriage & 4.47 & 1.67 to 11.96 & 0.0008 \\
TLR4 +896 G-allele carriage & 6.41 & 1.77 to 23.17 & 0.0103 \\
Age $\geqslant 50$ years & 5.74 & 1.99 to 16.55 & 0.0001 \\
Full-thickness burn $\geqslant 30 \% T B S A$ & 4.62 & 1.79 to 11.88 & 0.0002 \\
Female gender & 3.84 & 1.47 to 10.00 & 0.0055
\end{tabular}

Odds ratios were determined by multivariate logistic regression using a "best sub-sets" model. This analytical model selected the most parsimonious set of prognostic factors that best described the risk for severe sepsis.

\section{Stratification on clinical risk}

We hypothesised that the associations between the candidate SNPs and severe sepsis might have been influenced by the degree of clinical risk. Previous analysis of a large dataset determined that age $\geqslant 50$ years and full-thickness burn size $\geqslant 30 \%$ TBSA identified patients at increased risk for death. ${ }^{25}$ Patients were categorised according to the presence or absence of these clinical risk factors (full thickness burn size $\geqslant 30 \%$ TBSA and/or age $\geqslant 50$ years). The risk for severe sepsis and death according to clinical risk stratification is presented in table 6. A total of $76(48 \%)$ patients were younger than 50 years of age with full-thickness burns covering less than $30 \%$ TBSA; these patients constituted the low risk group. Some 74 $(47 \%)$ patients were either $\geqslant 50$ years old or had $\geqslant 30 \%$ TBSA full-thickness burns and nine $(6 \%)$ patients were both $\geqslant 50$ years of age with $\geqslant 30 \%$ TBSA full-thickness burns. Therefore, a total of 83 patients were categorised into the high risk group. The association between A-allele carriage at the TNF- $\alpha$ -308 SNP and severe sepsis was similar in both the high and low risk groups (Mantel-Haenszel $\chi^{2}=0.05 ; p=0.821$ ). However, the increased risk for severe sepsis associated with the TLR4 +896 G-allele was limited to the low risk group (Mantel-Haenszel $\chi^{2}=8.04 ; \quad p=0.005$ ). The unadjusted relative risk for the TLR $4+896 \mathrm{G}$-allele among low and high risk patients was 7.44 and 0.99 , respectively, versus 2.25 and 2.26 for the TNF- $\alpha-308$ A-allele (fig 1).

\section{DISCUSSION}

These results provide the first evidence that genetic polymorphisms within innate immunity loci are associated with an increased risk for severe sepsis after burn injury. Carriage of the TNF- $\alpha-308$ A- or the TLR4 +896 G-allele was

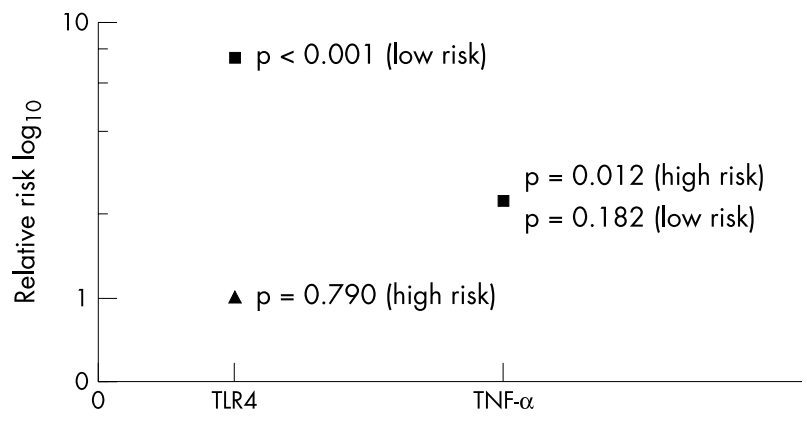

Figure 1 The patient population was stratified on clinical risk for severe sepsis, using age $\geqslant 50$ years and/or full thickness burn size $\geqslant 30 \%$ TBSA as cut points. The unadjusted relative risk for severe sepsis following burn injury that was associated with TLR4/TNF- $\alpha$ genotype in the low versus high clinical risk groups was then analysed in a Mantel-Haenszel test. While the relative risk associated with carriage of the TNF- $\alpha-308 \mathrm{~A}$ allele was similar in both groups, the relative risk for carriage of the TLR4 G-allele differed between risk groups. TLR4 genotype was significantly associated with increased risk for severe sepsis among low risk patients only.
Table 6 The frequency of severe sepsis and mortality following burn injury in high versus low clinical risk groups

\begin{tabular}{llll}
\hline & $\begin{array}{l}\text { Low clinical } \\
\text { risk }(\mathbf{n}=76)\end{array}$ & $\begin{array}{l}\text { High clinical } \\
\text { risk }(\mathbf{n}=83)\end{array}$ & p Value \\
\hline Severe sepsis & $8(11 \%)$ & $28(34 \%)$ & $<0.001$ \\
Death & $3(4 \%)$ & $22(27 \%)$ & $<0.001$ \\
\hline
\end{tabular}

The adverse outcomes of severe sepsis and death were more common among patients in the high clinical risk group. Clinical risk groups were stratified using age $\geqslant 50$ years of age and/or full thickness burn size $\geqslant 30 \%$ TBSA as cut points.

associated with an increased risk for developing severe sepsis. The increase in risk associated with carriage of variant alleles at these SNPs was comparable to the risk associated with traditional clinical factors such as age and full thickness burn size.

While there has been recent controversy regarding the validity of genetic association data, confidence in the legitimacy of our results was strengthened by independent evidence that the TLR4 +896 and TNF- $\alpha-308$ SNPs have functional relevance. That is to say, alternate alleles at these SNPs seem to impact protein abundance or function. For example, recent studies have suggested that altered TLR4 signalling plays a role in bacterial resistance as well as the development of sepsis and septic shock. ${ }^{26-29}$ TLR4 is a transmembrane protein that initiates a signalling cascade that triggers an innate immune response to endotoxin. ${ }^{30}{ }^{31}$ In mammals, TLR4 initiates a signal upon activation by CD14bound lipopolysaccharide (LPS) that is transmitted through a series of adapter molecules and protein kinases resulting in nuclear translocation of NF- $\mathrm{KB}$ and a subsequent cascade of inflammatory cytokines and chemokines. ${ }^{32-35}$ The nonsynonymous adenine to guanine $(A \rightarrow G)$ transition at nucleotide +896 of the human TLR4 mRNA that occurs within the extracellular domain of the TLR4 protein results in the substitution of asparagine with glycine at amino acid residue 299 (Asp299Gly). Carriers of the G-allele at this SNP exhibit reduced LPS responsiveness as well as an increased risk for septic shock and susceptibility to Gram-negative sepsis. ${ }^{14} 2936$ Furthermore, transient transfection experiments in THP-1 cells indicated that the 299Gly allele was able to disrupt TLR4 signalling. ${ }^{14}$ Importantly, adenoviral transfection of a wildtype TLR4 construct was able to rescue LPS responsiveness in airway epithelial cells and alveolar macrophages derived from individuals with TLR4 mutations. ${ }^{14}$ Finally, associations between altered TLR4 signalling and a number of inflammatory disease states have been reported..$^{13} 3738$

Similar evidence of a functional effect exists for the TNF- $\alpha$ -308 SNP. Importantly, TNF- $\alpha$ has been demonstrated to play a major role in the pathogenesis of sepsis and its complications after burn trauma. ${ }^{39-42}$ Furthermore, there is evidence that the guanine to adenine substitution $(G \rightarrow A)$ at nucleotide -308 within the TNF- $\alpha$ promoter affects transcriptional regulation of TNF- $\alpha .^{78}$ Carriage of the less common A-allele at this position has been associated with unfavourable clinical outcomes and increased risk of acquiring several infectious and inflammatory diseases in a number of clinical settings. ${ }^{83-45}$

It was of interest that carriage of variant alleles at TLR4 and TNF- $\alpha$ have a seemingly opposite impact upon the amplitude of the endotoxin response. While carriage of the TLR $4+896 \mathrm{G}$ allele appears to decrease the intensity of the LPS response signal, ${ }^{14}{ }^{16}$ the TNF- $\alpha-308 \mathrm{~A}$ allele is associated with an increased rate of TNF- $\alpha$ transcription. ${ }^{46}{ }^{47}$ In order to further investigate the effects of the TLR4 and TNF- $\alpha$ SNPs upon risk for severe sepsis, patients were stratified into low 
and high clinical risk groups using two established clinical risk factors: full thickness burn size $\geqslant 30 \%$ TBSA and/or age $\geqslant 50$ years. A Mantel-Haenszel test was used to evaluate interaction between clinical risk and carriage of variant alleles at the candidate SNPs. Interestingly, the test for homogeneity between high and low clinical risk groups was significant for the TLR4 +896 G-allele, indicating that the clinical risk status significantly impacted the effect of TLR4 +896 G-allele carriage. Carriage of the TLR4 G-allele was significantly associated with an increased risk for severe sepsis among low risk patients only. The biological implication of this observation may be that reduced toll pathway signalling by TLR4 $+896 \mathrm{G}$-allele carriers fails to control local infection in cases of lower clinical risk and that these uncontrolled local infections proceed to become systemic. Alternatively, when the clinical risk is sufficiently severe, stimulation of the endotoxin response through TLR4 is strong enough to overcome a genetic predisposition for reduced signalling. In the case of the TNF- $\alpha$ SNP, the higher level of transcription that has been ascribed to the -308 A-allele appears to increase risk for severe sepsis in all cases.

However, there is an important caveat to this reasoning: the Mantel-Haenszel results could have been statistically spurious. Stratification of our relatively small patient sample into clinical risk groups increased this possibility by effectively reducing statistical power. In addition, these results were the result of subgroup analysis, which is well known to inflate the likelihood of type I (false positive) error.

In addition, although we adjusted for ethnicity in our logistic regression, unmeasured genetic differences in this diverse cohort may have contributed to the risk for severe sepsis in unappreciated ways. Allelic frequencies of many polymorphisms are known to vary across ethnic groups and this variation may either reduce statistical power by generating undetected heterogeneity within the genomic background or produce spurious results if clinically relevant traits are in linkage disequilibrium with one or more candidate SNPs by chance. Further investigation with a much larger, preferably geographically distinct, patient population and/or the development of sophisticated statistical models will be required to fully resolve these issues.

In conclusion, this study provides strong evidence regarding the association of the TNF- $\alpha-308$ promoter and TLR4 +896 coding region polymorphisms with an increased risk for severe sepsis following burn trauma. Furthermore, the independent predictive value of A-allele carriage at the -308 position in the TNF- $\alpha$ promoter and G-allele carriage at TLR $4+896$ appear to impart the same risk as traditional clinical factors.

\section{ACKNOWLEDGEMENTS}

We thank Ms Audrey Cusano and Mr Thomas Wheeler for their outstanding technical contributions to this project.

\footnotetext{
Authors' affiliations

R C Barber, F A Rivera-Chavez, G F Purdue, J L Hunt, J W Horton, The Department of Surgery, The University of Texas Southwestern Medical Center, Dallas, TX, USA

C C Aragaki, Divisions of Epidemiology and Biostatistics, School of Public Health, Dallas Regional Campus, University of Texas Health Science Center at Houston, Dallas, TX, USA

This work was supported by NIGMS grant \#5P50GM021681-38.

Conflict of interest: none declared.

\section{REFERENCES}

1 Angus DC, Wax RS. Epidemiology of sepsis: an update. Crit Care Med 2001;29(7 suppl):S109-16.

2 Bone RC. Toward an epidemiology and natural history of SIRS (systemic inflammatory response syndrome). JAMA 1992;268(24):3452-5.
}

3 Friedman G, Silva E, Vincent JL. Has the mortality of septic shock changed with time? Crit Care Med 1998;26(12):2078-86.

4 O'Keefe GE, Hunt JL, Purdue GF. An evaluation of risk factors for mortality after burn trauma and the identification of gender-dependent differences in outcomes. J Am Coll Surg 2001;192(2):153-60.

5 Abraham E, Matthay MA, Dinarello CA, Vincent JL, Cohen J, Opal SM, Glauser M, Parsons P, Fisher CJ Jr, Repine JE. Consensus conference definitions for sepsis, septic shock, acute lung injury, and acute respiratory distress syndrome: time for a reevaluation. Crit Care Med 2000;28(1):232-5.

6 Sorensen TI, Nielsen GG, Andersen PK, Teasdale TW. Genetic and environmental influences on premature death in adult adoptees. N Engl J Med 1988;318(12):727-32

7 Mira JP, Cariou A, Grall F, Delclaux C, Losser MR, Heshmati F, Cheval C, Monchi M, Teboul JL, Riche F, Leleu G, Arbibe L, Mignon A, Delpech M, Dhainaut JF. Association of TNF2, a TNF-alpha promoter polymorphism, with septic shock susceptibility and mortality: a multicenter study. JAMA 1999;282(6):561-8

8 O'Keefe GE, Hybki DL, Munford RS. The G $\rightarrow$ A single nucleotide polymorphism at the -308 position in the tumor necrosis factor-alpha promoter increases the risk for severe sepsis after trauma. J Trauma 2002;52(5):817-26.

9 Knight JC, Kwiatkowski D. Inherited variability of tumor necrosis factor production and susceptibility to infectious disease. Proc Assoc Am Physicians 1999; 111 (4):290-8.

10 Wang $Y$, Kato N, Hoshida Y, Yoshida H, Taniguchi H, Goto T, Moriyama M, Otsuka M, Shiina S, Shiratori $Y$, Ito $Y$, Omata M. Interleukin-1 beta gene polymorphisms associated with hepatocellular carcinoma in hepatitis $C$ virus infection. Hepatology 2003;37(1):65-71.

11 Brull DJ, Montgomery HE, Sanders J, Dhamrait S, Luong L, Rumley A, Lowe GD, Humphries SE. Interleukin-6 gene $-174 \mathrm{~g}>\mathrm{c}$ and $-572 \mathrm{~g}>\mathrm{c}$ promoter polymorphisms are strong predictors of plasma interleukin-6 levels after coronary artery bypass surgery. Arterioscler Thromb Vasc Biol $2001 ; 21(9)$ : 1458-63.

12 Schluter B, Raufhake C, Erren M, Schotte H, Kipp F, Rust S, Van AH, Assmann $G$, Berendes E. Effect of the interleukin-6 promoter polymorphism $(-174 \mathrm{G} / \mathrm{C})$ on the incidence and outcome of sepsis. Crit Care Med 2002;30(1):32-7.

13 Schwartz DA. TLR4 and LPS hyporesponsiveness in humans. Int J Hyg Environ Health 2002:205(3):221-7.

14 Arbour NC, Lorenz E, Schutte BC, Zabner J, Kline JN, Jones M, Frees K, Watt JL, Schwartz DA. TLR4 mutations are associated with endotoxin hyporesponsiveness in humans. Nat Genet 2000;25(2):187-91.

15 Abraham L, Kroeger KM. Impact of the -308 TNF promoter polymorphism on the transcriptional regulation of the TNF gene: relevance to disease. J Leukoc Biol 1999;66(4):562-6.

16 LeVan TD, Bloom JW, Bailey TJ, Karp CL, Halonen M, Martinez FD, Vercelli D. A common single nucleotide polymorphism in the CD14 promoter decreases the affinity of $\mathrm{Sp}$ protein binding and enhances transcriptional activity. $J$ Immunol 2001;167(10):5838-44.

17 Kroeger KM, Steer JH, Joyce DA, Abraham L. Effects of stimulus and cell type on the expression of the -308 tumour necrosis factor promoter polymorphism. Cytokine 2000; 12(2): 110-9

18 Fishman D, Faulds G, Jeffery R, Mohammed-Ali V, Humphries S, Woo P. An interleukin-6 promoter polymorphism that influences gene transcription, plasma IL-6 levels and is associated with systemic-onset juvenile chronic arthritis. Eur Cytokine Netw 1998;9(3):364.

19 El Omar EM, Carrington M, Chow WH, McColl KE, Bream JH, Young HA, Herrera J, Lissowska J, Yuan CC, Rothman N, Lanyon G, Martin M, Fraumeni JF Jr, Rabkin CS. Interleukin-1 polymorphisms associated with increased risk of gastric cancer. Nature 2000;404(6776):398-402.

20 Baker SP, O’Neill B, Haddon W Jr, Long WB. The injury severity score: a method for describing patients with multiple injuries and evaluating emergency care. J Trauma 1974;14(3):187-96.

21 Miller SA, Dykes DD, Polesky HF. A simple salting out procedure for extracting DNA from human nucleated cells. Nucleic Acids Res 1988;16(3):1215.

22 Alderborn A, Kristofferson A, Hammerling U. Determination of singlenucleotide polymorphisms by real-time pyrophosphate DNA sequencing Genome Res 2000;10(8):1249-58.

23 Marshall JC, Cook DJ, Christou NV, Bernard GR, Sprung CL, Sibbald WJ. Multiple organ dysfunction score: a reliable descriptor of a complex clinical outcome. Crit Care Med 1995;23(10): 1638-52.

24 Fitzwater J, Purdue GF, Hunt JL, O'Keefe GE. The risk factors and time course of sepsis and organ dysfunction after burn trauma. J Trauma 2003;54(5):959-66.

25 Cumming J, Purdue GF, Hunt JL, O'Keefe GE. Objective estimates of the incidence and consequences of multiple organ dysfunction and sepsis after burn trauma. J Trauma 2001;50(3):510-5.

26 Chapes SK, Mosier DA, Wright AD, Hart ML. MHCIl, Tlr4 and Nrampl genes control host pulmonary resistance against the opportunistic bacterium Pasteurella pneumotropica. J Leukoc Biol 2001;69(3):381-6.

27 Ingalls RR, Lien E, Golenbock DT. Differential roles of TLR2 and TLR4 in the host response to Gram-negative bacteria: lessons from a lipopolysaccharidedeficient mutant of Neisseria meningitidis. J Endotoxin Res 2000;6(5):41 1-5.

28 Leveque G, Forgetta $\mathrm{V}$, Morroll S, Smith AL, Bumstead N, Barrow P, LoredoOsti JC, Morgan K, Malo D. Allelic variation in TLR4 is linked to susceptibility to Salmonella enterica serovar Typhimurium infection in chickens. Infect Immun 2003;71(3):1116-24.

29 Lorenz E, Mira JP, Frees KL, Schwartz DA. Relevance of mutations in the TLR4 receptor in patients with gram-negative septic shock. Arch Intern Med 2002;162(9): 1028-32. 
30 Smirnova I, Poltorak A, Chan EK, McBride C, Beutler B. Phylogenetic variation and polymorphism at the toll-like receptor 4 locus (TLR4). Genome Biol 2000;1(1):RESEARCH002.

31 Belvin MP, Anderson KV. A conserved signaling pathway: the Drosophila tolldorsal pathway. Annu Rev Cell Dev Biol 1996;12:393-416.

32 O'Neill LA. Signal transduction pathways activated by the IL-1 receptor/tolllike receptor superfamily. Curr Top Microbiol Immunol 2002;270:47-61.

33 Akira S, Takeda K, Kaisho T. Toll-like receptors: critical proteins linking innate and acquired immunity. Nat Immunol 2001;2(8):675-80.

34 An H, Yu Y, Zhang M, Xu H, Qi R, Yan X, Liu S, Wang W, Guo Z, Guo J, $Q$ in Z, Cao X. Involvement of ERK, p38 and NF-kappaB signal transduction in regulation of TLR2, TLR4 and TLR9 gene expression induced by lipopolysaccharide in mouse dendritic cells. Immunology 2002; 106(1):38-45.

35 Beutler B. Tr 4: central component of the sole mammalian LPS sensor. Curr Opin Immunol 2000;12(1):20-6.

36 Agnese DM, Calvano JE, Hahm SJ, Coyle SM, Corbett SA, Calvano SE, Lowry SF. Human toll-like receptor 4 mutations but not CD 14 polymorphisms are associated with an increased risk of gram-negative infections. J Infect Dis 2002;186(10): 1522-5.

37 Ferrand PE, Fujimoto T, Chennathukuzhi V, Parry S, Macones GA, Sammel M, Kuivaniemi $H$, Romero R, Strauss JF III. The CARD 15 2936insC mutation and TLR4 896 A $>$ G polymorphism in African Americans and risk of preterm premature rupture of membranes (PPROM). Mol Hum Reprod 2002;8(1 1): 1031-4.

38 Frantz S, Kobzik L, Kim YD, Fukazawa R, Medzhitov R, Lee RT, Kelly RA. Toll4 (TLR4) expression in cardiac myocytes in normal and failing myocardium. J Clin Invest 1999; 104(3):271-80.

39 Marano MA, Fong Y, Moldawer LL, Wei H, Calvano SE, Tracey KJ, Barie PS, Manogue K, Cerami A, Shires GT, Lowry SF. Serum cachectin tumor necrosis factor in critically ill patients with burns correlates with infection and mortality. Surg Gynecol Obstet 1990;170(1):32-8.

40 Drost AC, Burleson DG, Cioffi WG, Jordan BS, Mason AD, Pruitt BA. Plasma cytokines following thermal-injury and their relationship with patient mortality, burn size, and time postburn. J Trauma-Injury Infect Crit Care 1993;35(3):335-9.

41 Endo S, Inada K, Yamada Y, Kasai T, Takakuwa T, Nakae H, Kikuchi M, Hoshi S, Suzuki M, Yamashita H, Yoshida M. Plasma tumor-necrosisfactor-alpha (TNF-alpha) levels in patients with burns. Burns 1993;19(2): 124-7.

42 Arslan E, Yavuz M, Dalay C. The relationship between tumor necrosis factor (TNF)-alpha and survival following granulocyte-colony stimulating factor (G-CSF) administration in burn sepsis. Burns 2000;26(6):521-4.

43 Knight JC, Udalova I, Hill AV, Greenwood BM, Peshu N, Marsh K, Kwiatkowski D. A polymorphism that affects OCT-1 binding to the TNF promoter region is associated with severe malaria. Nat Genet 1999;22(2): 145-50.

44 Sankaran D, Asderakis A, Ashraf S, Roberts ISD, Short CD, Dyer PA, Sinnott PJ, Hutchinson IV. Cytokine gene polymorphisms predict acute graft rejection following renal transplantation. Kidney Int 1999;56(1):281-8.

45 Nadel S, Newport MJ, Booy R, Levin M. Variation in the tumor necrosis factoralpha gene promoter region may be associated with death from meningococcal disease. J Infect Dis 1996;174(4):878-80.

46 Wilson AG, Symons JA, McDowell TL, McDevitt HO, Duff GW. Effects of a polymorphism in the human tumor necrosis factor alpha promoter on transcriptional activation. Proc Natl Acad Sci U S A 1997;94(7):3195-9.

47 Kroeger KM, Carville KS, Abraham $\amalg$. The -308 tumor necrosis factor-alpha promoter polymorphism effects transcription. Mol Immunol 1997;34(5):391-9.

\section{Retraction statement}

The authors of the following manuscript Ninis VN, Kýlýnç MO, Kandemir M, Daõlý E, Tolun. High Frequency of 9T and CFTR Mutations in Children with Idiopathic Bronchiectasis. J Med Genet 2003;40:530-5, are retracting it because the polythymidine track genotype data are not correct. Recently the authors repeated the genotyping or 17 of the subjects to check whether the reported genotypes were correct and found out that they were not. At the time of submission of the manuscript, the authors were very confident of the data, since they had employed two independent methods for the genotyping of all subjects. However subsequently the authors were prompted to the recheck Vasiliki N Ninis results and have been unable to confirm them. The authors regret that we did not find out prior to publication. 